\title{
Zerovalent bismuth nanoparticles inhibit Streptococcus mutans growth and formation of biofilm
}

This article was published in the following Dove Press journal:

International Journal of Nanomedicine

21 April 2012

Number of times this article has been viewed

Rene Hernandez-Delgadillo'

Donaji Velasco-Arias ${ }^{2}$

David Diaz ${ }^{2}$

Katiushka Arevalo-Niño'

Marianela Garza-Enriquez'

Myriam A De la Garza-

Ramos'

\section{Claudio Cabral-Romero'}

'Instituto de Biotecnologia, Centro de Investigacion y Desarrollo en Ciencias de la Salud, CIDICS, Facultad de Odontologia, Universidad Autonoma de Nuevo Leon, UANL, Monterrey, Nuevo Leon, ${ }^{2}$ Facultad de Quimica, Universidad Nacional Autonoma de Mexico, Distrito Federal, Mexico
Correspondence: Claudio CabralRomero

Universidad Autonoma de Nuevo Leon, UANL, Facultad de Odontologia, Centro de Investigacion y Desarrollo en Ciencias de la Salud, CIDICS, Gonzalitos Norte y Carlos Canseco, Mitras Centro, Monterrey, Nuevo Leon, Mexico, CP 64460

Tel +528183294000 ext 1816

$\mathrm{Fax}+5283294000$ ext 1727

Email claudiohubble@hotmail.com
Background and methods: Despite continuous efforts, the increasing prevalence of resistance among pathogenic bacteria to common antibiotics has become one of the most significant concerns in modern medicine. Nanostructured materials are used in many fields, including biological sciences and medicine. While some bismuth derivatives has been used in medicine to treat vomiting, nausea, diarrhea, and stomach pain, the biocidal activity of zerovalent bismuth nanoparticles has not yet been studied. The objective of this investigation was to analyze the antimicrobial activity of bismuth nanoparticles against oral bacteria and their antibiofilm capabilities.

Results: Our results showed that stable colloidal bismuth nanoparticles had $69 \%$ antimicrobial activity against Streptococcus mutans growth and achieved complete inhibition of biofilm formation. These results are similar to those obtained with chlorhexidine, the most commonly used oral antiseptic agent. The minimal inhibitory concentration of bismuth nanoparticles that interfered with $S$. mutans growth was $0.5 \mathrm{mM}$.

Conclusion: These results suggest that zerovalent bismuth nanoparticles could be an interesting antimicrobial agent to be incorporated into an oral antiseptic preparation.

Keywords: zerovalent bismuth nanoparticles, antimicrobial agent, biofilm, Streptococcus mutans

\section{Introduction}

Bacteria in nature do not grow in nutrient-rich medium nor in individual form. These microorganisms live in association within communities containing other microorganisms in a cooperative form, known as biofilm. Biofilms can form on all kinds of surfaces and interfaces, including the human body. ${ }^{1}$ The most common biofilm is dental plaque in the oral cavity, with Streptococcus mutans being the main etiological agent of dental caries worldwide. ${ }^{2,3}$ S. mutans has also been identified in cases of endocarditis, where it colonizes the endocardium and cardiac valves, probably due to an ability to adhere to solid surfaces and form a biofilm. ${ }^{4}$

Despite continuous efforts on the part of the pharmaceutical industry, increasing resistance of microorganisms to common antibiotics has become an important issue in current medicine. ${ }^{5}$ The absence of new alternatives to treat multidrug-resistant pathogenic bacteria efficiently is a real problem, and there is an urgent need to synthesize new broad-spectrum drugs to fight antimicrobial resistance.

Bismuth is a metallic element of the VA group, together with nitrogen, phosphorus, antimony, and arsenic. Its oxidation numbers are +3 and +5 . It is found in the same proportions as silver in the Earth's crust, and it occupies the 73rd place in abundance. 
Typically, it is found as bismuthinite (bismuth sulfide), bismite (bismuth oxide), and bismuthite (bismuth carbonate). ${ }^{6}$ Mexico is the second most important producer of bismuth worldwide after China. Bismuth is used in the manufacture of pharmaceutical products, cosmetics, catalysts, pigments, electronics, and alloys. In medicine, bismuth subsalicylate has been used as an antidiarrheal agent to treat nausea, vomiting, and stomach pain. ${ }^{7}$

Recently, zerovalent bismuth nanoparticles have attracted interest because of their potential application in electronic devices and magnetic sensors. ${ }^{8}{ }^{8}$ Nanoparticles have an increased surface area and therefore have increased interaction with biological targets. However, the potential for use of zerovalent bismuth nanoparticles in medicine is currently unknown. In this work, we present early evidence of the inhibitory antimicrobial effect of bismuth nanoparticles against growth of S. mutans and its capability to form a biofilm. The biocidal activity of bismuth nanoparticles was very similar to that obtained with chlorhexidine, a commonly used oral antiseptic.

\section{Materials and methods}

\section{Synthesis of zerovalent bismuth nanoparticles}

The following chemical reagents and methods were used for the synthesis of zerovalent bismuth nanoclusters: bismuth nitrate pentahydrate $\left[\mathrm{Bi}\left(\mathrm{NO}_{3}\right)_{3} .5 \mathrm{H}_{2} \mathrm{O}, 98 \%\right.$, Sigma, St Louis, MO], sodium citrate dihydrate $\left[\mathrm{Na}_{3}\left(\mathrm{C}_{6} \mathrm{H}_{5} \mathrm{O}_{7}\right) \cdot 2 \mathrm{H}_{2} \mathrm{O}\right.$, $99 \%$, Sigma], sodium borohydride $\left(\mathrm{NaBH}_{4}, 99 \%\right.$, Sigma), dimethyl sulfoxide (Baker, 99.02\%, Avantor, Phillipsburg, NJ), methanol (99.8\%, Merck, Whitehouse Station, NJ), argon (99.99\%, Praxair Inc, Biddeford, ME), and $4 \AA$ molecular sieves (Linde, Tulsa, OK). All reagents were used as received. For a typical preparation of stable colloids, zerovalent bismuth nanoparticles were synthesized by reduction of bismuth nitrate $\mathrm{Bi}\left(\mathrm{NO}_{3}\right)_{3} \cdot 5 \mathrm{H}_{2} \mathrm{O}$ and were then stabilized by sodium citrate $\mathrm{Na}_{3}\left(\mathrm{C}_{6} \mathrm{H}_{5} \mathrm{O}_{7}\right) \cdot 2 \mathrm{H}_{2} \mathrm{O}$. Specifically, $0.0148 \mathrm{~g}$ of $\mathrm{Na}_{3}\left(\mathrm{C}_{6} \mathrm{H}_{5} \mathrm{O}_{7}\right) \cdot 2 \mathrm{H}_{2} \mathrm{O}$ were dissolved in $100 \mu \mathrm{L}$ of water and $24 \mathrm{~mL}$ of dimethyl sulfoxide was added. Next, $0.0242 \mathrm{~g}$ of $\mathrm{Bi}\left(\mathrm{NO}_{3}\right)_{3} \cdot 5 \mathrm{H}_{2} \mathrm{O}$ were added to the mixture. The mixture was fizzed with argon for 15 minutes, and $1 \mathrm{~mL}$ of sodium borohydride in methanol $0.2 \mathrm{M} \mathrm{NaBH}_{4}$ was added as reducing agent. The final concentrations of each $\mathrm{Na}_{3}\left(\mathrm{C}_{6} \mathrm{H}_{5} \mathrm{O}_{7}\right) \cdot 2 \mathrm{H}_{2} \mathrm{O}$ and $\mathrm{Bi}\left(\mathrm{NO}_{3}\right)_{3} \cdot 5 \mathrm{H}_{2} \mathrm{O}$ were $2 \times 10^{-3} \mathrm{M}$.

\section{Characterization of zerovalent bismuth nanoparticles}

The size, distribution, and morphology of the zerovalent bismuth nanoparticles were determined by high-resolution transmission electron microscopy (TEM) using a JEM 2010 FasTem microscope equipped with Digital Micrograph 1.2 software and a high angle annular dark field detector as well as energy-dispersive and GIF spectrophotometers, at a voltage of $200 \mathrm{kV}$. Conventional high-resolution TEM images were obtained in a Scherzer defocused condition. A drop of the colloidal nanoparticles was deposited onto 200 mesh copper grids coated with a carbon/collodion layer. The bismuth rhombohedral phase identification was obtained by x-ray diffraction patterns, recorded on a Bruker $\mathrm{D}-8$ Advance diffractometer using $\mathrm{Cu} \mathrm{K} \alpha$ radiation $(20 \mathrm{~mA}$, $40 \mathrm{kV}, \lambda=1.5418 \AA$ ).

\section{Antimicrobial activity against $S$. mutans}

The antimicrobial effect of the bismuth nanoparticles on growth of $S$. mutans (strain AU130, ATCC 700611, Manassas, VA) was determined using the 3-(4,5-dimethylthiazol-2-yl)2,5-diphenyltetrazolium bromide (MTT) assay (Biotium, Hayward, CA), ${ }^{10,11}$ following the instructions of the manufacturer. S. mutans was grown in trypticase soy broth (BD Difco, Sparks MD) at $37^{\circ} \mathrm{C}$ overnight in aerobic conditions. The bacteria were counted using a Neubauer chamber, and $1 \times 10^{4}$ cells were inoculated in $100 \mu \mathrm{L}$ of trypticase soy broth medium in a 96-well polystyrene plate. Three wells with only trypticase soy broth medium were used as controls for growth of $S$. mutans. Chlorhexidine $0.12 \%$ (Ultradent Products, South Jordan, UT) was used as a positive antimicrobial control. We used $2 \mathrm{mM}$ of zerovalent bismuth nanoparticles to interfere with bacterial growth. The 96-well plate was incubated at $37^{\circ} \mathrm{C}$ overnight. Next, $10 \mu \mathrm{L}$ of MTT was added to each well, and the plate was protected against light and incubated at $37^{\circ} \mathrm{C}$ for 2 hours. Next, $200 \mu \mathrm{L}$ of dimethyl sulfoxide was added to dissolve the reduced MTT. The amount of live cells was determined using a microplate absorbance reader (Biorad, Philadelphia, PA) at $595 \mathrm{~nm}$. The experiment was repeated three times, and the measured optical density was analyzed by descriptive statistics.

\section{Antibiofilm activity}

The antibiofilm activity of the bismuth nanoparticles was determined by fluorescence microscopy, following the methodology described above. To observe the biofilm, SYTO 9 green dye (Invitrogen, Carlsbad, CA) was added at a final concentration of $20 \mu \mathrm{M} .^{12,13}$ The 96-well plate was incubated for 30 minutes at room temperature and protected against light. The $S$. mutans biofilm was visualized using a Carl Zeiss Z1 Axio Inverter microscope (Thornwood, NY) at $485 \mathrm{~nm}$. 


\section{Determination of MIC for zerovalent bismuth nanoparticles}

The minimal inhibitory concentration (MIC) was determined as previously described. ${ }^{14}$ Briefly, it was obtained by dilution of a 5 tube in the McFarland scale with $1 \times 10^{9}$ colonyforming units. $S$. mutans was grown in trypticase soy broth agar and incubated at $37^{\circ} \mathrm{C}$ for 24 hours. One colony was inoculated in $5 \mathrm{~mL}$ of trypticase soy broth medium and incubated at $37^{\circ} \mathrm{C}$ for 24 hours. The bacteria count was determined with a Neubauer chamber. Tubes with a final concentration of $1 \times 10^{6}$ colony-forming units were obtained by dilution of a 5 tube in the McFarland scale. The bismuth nanoparticle solution was diluted to final concentrations of $2,1.5,1,0.5,0.25$, and $0.125 \mathrm{mM}$. Next, $1 \mathrm{~mL}$ of zerovalent bismuth nanoparticles was mixed as a bacterial suspension and incubated at $37^{\circ} \mathrm{C}$ for 18 hours. The MIC was determined from the presence or absence of turbidity in the different tubes containing the nanoparticles. Chlorhexidine $0.12 \%$ was used as a positive control for inhibition.

\section{Results}

\section{Synthesis of zerovalent bismuth nanoparticles}

The colloidal dispersions of zerovalent bismuth nanoparticles prepared from $2 \times 10^{-4} \mathrm{M} \mathrm{Bi}\left(\mathrm{NO}_{3}\right)_{3} \cdot 5 \mathrm{H}_{2} \mathrm{O}, 4 \times 10^{-4} \mathrm{M}$ $\mathrm{Na}_{3}\left(\mathrm{C}_{6} \mathrm{H}_{5} \mathrm{O}_{7}\right) \cdot 2 \mathrm{H}_{2} \mathrm{O}$, and $4 \times 10^{-4} \mathrm{M} \mathrm{NaBH}_{4}$ in dimethyl sulfoxide showed a narrow size distribution and a spherical form, with an average size of $3.3 \pm 0.97 \mathrm{~nm}$ (see Figure 1 for a typical particle). This mean size is the smallest reported in the literature.

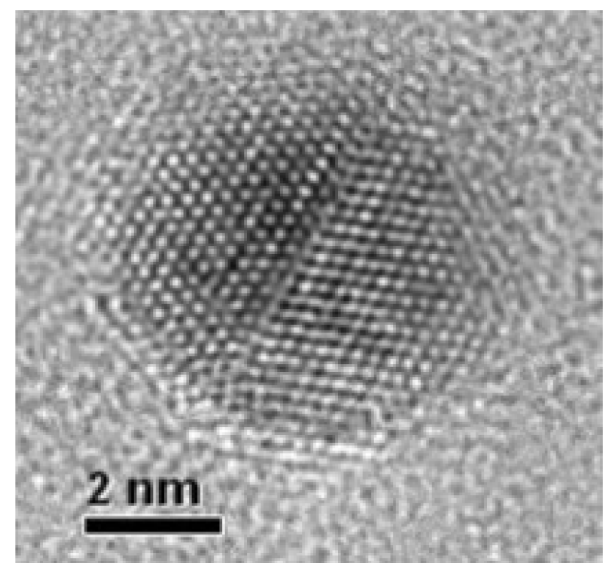

Figure I High-resolution transmission electron microscopic image of an isolated zerovalent bismuth nanoparticle.

Notes: The colloidal sample to obtain this image was prepared a few minutes before the microscopy session. Final concentrations of the chemical reagents are $2 \times 10^{-3} \mathrm{M} \mathrm{Bi}\left(\mathrm{NO}_{3}\right)_{3} \cdot 5 \mathrm{H}_{2} \mathrm{O}, 4 \times 10^{-4} \mathrm{M} \mathrm{Na}_{3}\left(\mathrm{C}_{6} \mathrm{H}_{5} \mathrm{O}_{7}\right) \cdot 2 \mathrm{H}_{2} \mathrm{O}$, and $4 \times 10^{-4} \mathrm{M}$ $\mathrm{NaBH} 4$ in dimethyl sulfoxide.

\section{Antimicrobial activity against S. mutans}

To explore the possible antimicrobial activity of zerovalent bismuth nanoparticles, their effect on $S$. mutans growth was determined. The results show that these nanoparticles reduced the number of bacteria by $69 \%$, in comparison with bacteria grown in medium alone (Figure 2). Similarly, treatment with $0.12 \%$ chlorhexidine (inhibition control) achieved a $63 \%$ reduction in the number of bacteria when compared with nontreated cells (Figure 2). To rule out any antimicrobial effect of dimethyl sulfoxide, it was added to the $S$. mutans cultures and no antimicrobial effect was detected after overnight incubation under our experimental conditions (data not shown). It is important to emphasize that zerovalent bismuth nanoparticles were stable to temperatures lower than $50^{\circ} \mathrm{C}$ following their characterization. Because all experiments were performed at $37^{\circ} \mathrm{C}$, no additional controls were used to determine the stability of zerovalent bismuth nanoparticles.

\section{Inhibitory effect on biofilm}

In the previous experiment, we measured the antimicrobial activity of zerovalent bismuth nanoparticles. In order to analyze for possible biofilm inhibition of $S$. mutans by bismuth nanoclusters, the antibiofilm activity of the nanoparticles was determined by fluorescence microscopy. The results show complete inhibition of biofilm formation by chlorhexidine (Figure 3B) and zerovalent bismuth nanoparticles (Figure 3C), compared with controls (Figure 3A). The results did not change when the zerovalent bismuth nanoparticles were added at different post-inoculation times. We tested the inhibitory activity on biofilm at 6 and 18 hours postinoculation, and obtained similar results (data not shown).

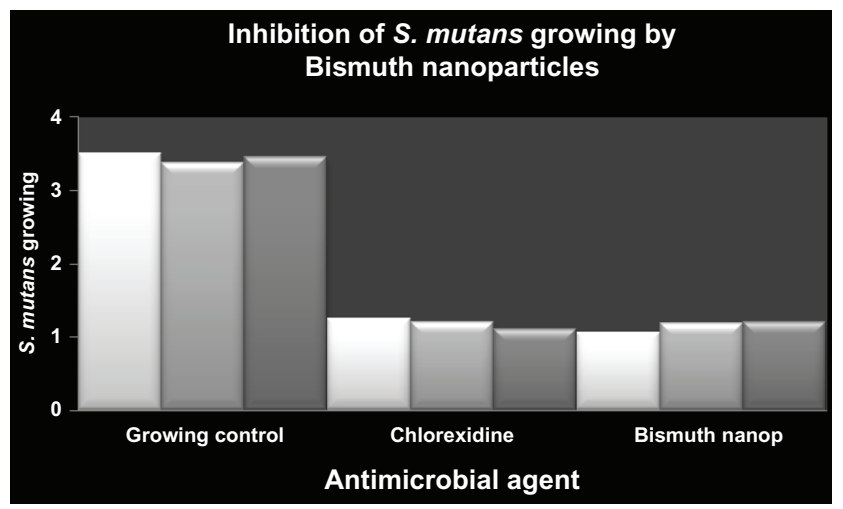

Figure 2 Antimicrobial activity of zerovalent bismuth nanoparticles against Streptococcus mutans growth.

Notes: The y axis shows the optical density units of S. mutans growth. S. mutans culture without any inhibitor was used as growing control and chlorhexidine $0.12 \%$ as a positive inhibition control. Zerovalent bismuth nanoparticles were used at a final concentration of $2 \mathrm{mM}$. 

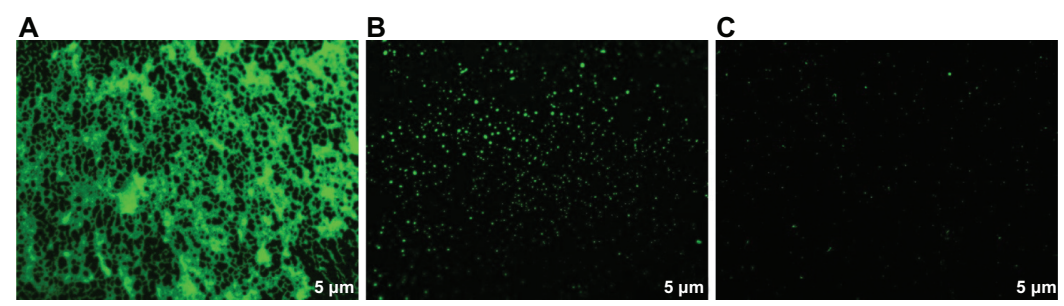

Figure 3 Inhibition of Streptococcus mutans biofilm detected by fluorescence microscopy.

Notes: S. mutans culture without any inhibitor was used as growing control and chlorhexidine $0.12 \%$ as a positive inhibition control. Zerovalent bismuth nanoparticles were used at a final concentration of $2 \mathrm{mM}$.

These data indicate that zerovalent bismuth nanoparticles had antibiofilm activity which was as effective as that of chlorhexidine.

\section{Determination of MIC}

In order to characterize the antimicrobial activity of the bismuth nanoclusters, we determined the MIC of the zerovalent bismuth nanoparticles. The result obtained was $0.5 \mathrm{mM}$. This result is important in terms of knowing the minimal effective quantity of zerovalent bismuth nanoparticles required to inhibit $S$. mutans growth.

\section{Discussion}

Nanotechnology is a new discipline with many applications in fields like biological sciences and medicine. Nanomaterials are applied as coating materials, as well as in treatment and diagnosis. ${ }^{15}$ Nanoparticles of titanium, silver, diamond, iron oxide, carbon nanotubes, and biodegradable polymers have been studied for their use in diagnosis and treatment. Nanoparticles with antimicrobial activity have been reported, including ones containing silver, copper oxide, and selenium. ${ }^{16-18}$ The advantages of nanoparticles are their high surface-to-volume ratios, their quantum confinement, and their nanoscale sizes, which allow more active sites to interact with biological systems, including bacteria. This is the most important difference between nanoparticles and typical antimicrobial agents, and could minimize the risk of developing antimicrobial resistance.

The mechanism of antimicrobial activity for nanoparticles is not completely understood, and their precise mechanism of action against bacteria remains to be fully elucidated. Several studies have shown that a positive charge on the metal ion is critical for antimicrobial activity, allowing for electrostatic attraction between the negative charge on the bacterial cell membrane and the positive charge on the nanoparticle. ${ }^{19}$ It has been reported that silver nanoparticles can damage DNA, alter gene expression, and affect membrane-bound respiratory enzymes. ${ }^{20-22}$
Here we present early evidence of the antimicrobial activity of zerovalent bismuth nanoparticles. Their efficacy in inhibiting $S$. mutans growth was comparable with that of chlorhexidine. The MIC of zerovalent bismuth nanoparticles for bacterial growth inhibition was $0.5 \mathrm{mM}$, which should be taken into account if they are to be incorporated into a mouthwash. Our results indicate that these nanoparticles as antimicrobial agents are as good as chlorhexidine, which is the most commonly used oral antiseptic agent. Previously it has been reported that silver, copper oxide, and selenium nanoparticles have antimicrobial activity. ${ }^{16-18}$ In fact, silver nanoparticles have been used to prevent biofilm formation on surfaces for both biomedical and more general use. ${ }^{23}$

In order to determine if zerovalent bismuth nanoparticles have the potential to interfere with $S$. mutans biofilm formation, we studied the antibiofilm activity of these nanoparticles. Surprisingly, they completely prevented biofilm formation. This effect was unexpected, given that zerovalent bismuth nanoparticles would only reduce cell growth and not completely inhibit it. We hypothesize that, since $69 \%$ of cells were inactivated by these nanoparticles, cell survival was not sufficient to form a biofilm. Survival bacteria were probably stressed due to the presence of zerovalent bismuth nanoparticles and it is possible that they were lost during washing out of the excess dye. In the presence of chlorhexidine and zerovalent bismuth nanoparticles, we only observed cellular debris on a dark background, comprising mainly DNA from dead bacteria with accumulation of dye. Morphologically, these dye accumulations differ from bacterial biofilm.

In this work, we focused on the effectiveness of zerovalent bismuth nanoparticles in inhibiting growth of $S$. mutans. Overall, the experimental data suggest that these nanoparticles could be an interesting alternative to combat bacterial infections underlying biofilms. The properties of these nanoparticles could be used in oral health, supporting the antimicrobial activity of oral antiseptics. Further experiments 
will be necessary to determine the possible toxicity of such nanoparticles in human fibroblast culture and to analyze their potential use in humans. In conclusion, we report that bismuth nanoparticles have antimicrobial activity against growth of S. mutans, as well as antibiofilm activity.

\section{Acknowledgments}

The authors wish to thank P Santiago-Jacinto and L Rendon from the Institute of Physics of National Autonomous University of Mexico (IF-UNAM) for obtaining TEM images. D Velasco-Arias and R Hernandez-Delgadillo wish to thank CONACyT for a scholarship. D Diaz and C CabralRomero also wish to thank CONACyT for financing the projects 132094 and 141616. This work was also supported by further grants from PROMEP-SEP (103.5/11/6627) and PAICYT-UANL-2011 to CCR.

\section{Disclosure}

The authors report no conflicts of interest in this work.

\section{References}

1. Costerton JW. Overview of microbial biofilms. J Ind Microbiol. 1995;15(3):137-140.

2. Costerton JW. Introduction to biofilm. Int J Antimicrob Agents. 1999;11(3-4):217-221.

3. Jenkinson HF. Adherence and accumulation of oral streptococci. Trends Microbiol. 1994;2(6):209-212.

4. Guntheroth WG. How important are dental procedures as a cause of infective endocarditis? Am J Cardiol. 1984;54(7):797-801.

5. Falagas ME, Fragoulis KN, Karydis I. A comparative study on the cost of new antibiotics and drugs of other therapeutic categories. PloS One. 2006;1:e11.

6. Kirk RE, Othmer DF. Encyclopedia of Chemical Technology. 3rd ed. New York, NY: Chichester, Wiley; 1980.

7. Figueroa-Quintanilla D, Salazar-Lindo E, Sack RB, et al. A controlled trial of bismuth subsalicylate in infants with acute watery diarrheal disease. N Engl J Med. 1993;328(23):1653-1658.
8. Zhang Z, Yu K, Bai D, Zhu Z. Synthesis and electrochemical sensing toward heavy metals of bunch-like bismuth nanostructures. Nanoscale Res Lett. 2009;5(2):398-402.

9. Chen R, So MH, Yang J, Deng F, Che CM, Sun H. Fabrication of bismuth subcarbonate nanotube arrays from bismuth citrate. Chem Commun (Camb). 2006;21:2265-2267.

10. Mosmann T. Rapid colorimetric assay for cellular growth and survival: application to proliferation and cytotoxicity assays. J Immunol Methods. 1983;65(1-2):55-63.

11. Liu Y, Peterson DA, Kimura H, Schubert D. Mechanism of cellular 3-(4,5-dimethylthiazol-2-yl)-2,5-diphenyltetrazolium bromide (MTT) reduction. J Neurochem. 1997;69(2):581-593.

12. Yue H, Eastman PS, Wang BB, et al. An evaluation of the performance of cDNA microarrays for detecting changes in global mRNA expression. Nucleic Acids Res. 2001;29(8):E41.

13. Frey T. Nucleic acid dyes for detection of apoptosis in live cells. Cytometry. 1995;21(3):265-274.

14. Andrews JM. Determination of minimum inhibitory concentrations. J Antimicrob Chemother. 2001;48 Suppl 1:5-16.

15. Colvin VL. The potential environmental impact of engineered nanomaterials. Nat Biotechnol. 2003;21(10):1166-1170.

16. Sondi I, Salopek-Sondi B. Silver nanoparticles as antimicrobial agent: a case study on E. coli as a model for Gram-negative bacteria. J Colloid Interface Sci. 2004;275(1):177-182.

17. Ren G, Hu D, Cheng EW, Vargas-Reus MA, Reip P, Allaker RP. Characterisation of copper oxide nanoparticles for antimicrobial applications. Int J Antimicrob Agents. 2009;33(6):587-590.

18. Tran PA, Webster TJ. Selenium nanoparticles inhibit Staphylococcus aureus growth. Int J Nanomedicine. 2011;6:1553-1558.

19. Kim JS, Kuk E, Yu KN, et al. Antimicrobial effects of silver nanoparticles. Nanomedicine. 2007;3(1):95-101.

20. Feng QL, Wu J, Chen GQ, Cui FZ, Kim TN, Kim JO. A mechanistic study of the antibacterial effect of silver ions on Escherichia coli and Staphylococcus aureus. J Biomed Mater Res. 2000;52(4):662-668.

21. Yamanaka M, Hara K, Kudo J. Bactericidal actions of a silver ion solution on Escherichia coli, studied by energy-filtering transmission electron microscopy and proteomic analysis. Appl Environ Microbiol. 2005;71(11):7589-7593.

22. Bragg PD, Rainnie DJ. The effect of silver ions on the respiratory chain of Escherichia coli. Can J Microbiol. 1974;20(6):883-889.

23. Sambhy V, MacBride MM, Peterson BR, Sen A. Silver bromide nanoparticle/polymer composites: dual action tunable antimicrobial materials. J Am Chem Soc. 2006;128(30):9798-9808.
International Journal of Nanomedicine

\section{Publish your work in this journal}

The International Journal of Nanomedicine is an international, peerreviewed journal focusing on the application of nanotechnology in diagnostics, therapeutics, and drug delivery systems throughout the biomedical field. This journal is indexed on PubMed Central, MedLine, CAS, SciSearch ${ }^{\circledR}$, Current Contents ${ }^{\circledR} /$ Clinical Medicine,

\section{Dovepress}

Journal Citation Reports/Science Edition, EMBase, Scopus and the Elsevier Bibliographic databases. The manuscript management system is completely online and includes a very quick and fair peer-review system, which is all easy to use. Visit http://www.dovepress.com/ testimonials.php to read real quotes from published authors. 